\title{
Lusioersily
}

\section{Postural Sway, Balance Confidence, and Fear of Falling in Women With Knee Osteoarthritis in Comparison to Matched Controls}

Taglietti, M., Dela Bela, LF., Dias, JM., Pelegrinelli, AR., Nogueira, JF., Batista Júnior, JP., Carvalho, RG., McVeigh, JG., Facci, LM., Moura, FA., \& Cardoso, JR. (2016). Postural Sway, Balance Confidence, and Fear of Falling in Women With Knee Osteoarthritis in Comparison to Matched Controls. PM \& R, 9, 31167-31174. https://doi.org/10.1016/j.pmrj.2016.11.003

Link to publication record in Ulster University Research Portal

Published in:

$P M \& R$

Publication Status:

Published online: 19/11/2016

DOI:

10.1016/j.pmrj.2016.11.003

Document Version

Author Accepted version

\section{General rights}

Copyright for the publications made accessible via Ulster University's Research Portal is retained by the author(s) and / or other copyright owners and it is a condition of accessing these publications that users recognise and abide by the legal requirements associated with these rights.

\section{Take down policy}

The Research Portal is Ulster University's institutional repository that provides access to Ulster's research outputs. Every effort has been made to ensure that content in the Research Portal does not infringe any person's rights, or applicable UK laws. If you discover content in the Research Portal that you believe breaches copyright or violates any law, please contact pure-support@ulster.ac.uk. 
1 Title: Postural sway, balance confidence and fear of falling in women with knee

2 osteoarthritis in comparison to matched controls

3

4 Author names and affiliations: Marcelo Taglietti ${ }^{1}, \mathrm{PhD}$, Laís Faganello Dela Bela ${ }^{1}, \mathrm{MSc}$,

5 Josilainne Marcelino Dias ${ }^{1}$, PhD, Post-Doc Fellow, Alexandre Roberto Marcondes

6 Pelegrinelli ${ }^{1}, \mathrm{PT}$, Jéssyca Fernandes Nogueira ${ }^{1}$, MSc, João Pedro Batista Júnior ${ }^{1}, \mathrm{PhD}$,

7 Rodrigo Gustavo da Silva Carvalho ${ }^{1}, \mathrm{MSc}$, Joseph Gerard McVeigh ${ }^{2}, \mathrm{PhD}$, Ligia Maria

8 Facci $^{1}, \mathrm{PhD}$, Felipe Arruda Moura, $\mathrm{PhD}^{3}$ and Jefferson Rosa Cardoso ${ }^{1}, \mathrm{PhD}$.

9

$10{ }^{1}$ Laboratory of Biomechanics and Clinical Epidemiology, PAIFIT Research Group,

11 Universidade Estadual de Londrina, Londrina, PR, Brazil.

$12{ }^{2}$ Centre for Health and Rehabilitation Technologies (CHaRT), School of Health Sciences,

13 University of Ulster, Jordanstown, Northern Ireland, UK.

$14{ }^{3}$ Sports Science Centre, Universidade Estadual de Londrina, Londrina, PR, Brazil.

16 Jefferson Rosa Cardoso

17 Av. Robert Kock, 60. Londrina - PR, Brazil. 86038-440.

18 Phone: 55 (43) 3371.2649.

19 Fax: 55 (43) 3371.2459.

20 E-mail: jeffcar@uel.br

22 Funding: FINEP (MCT/AÇÃO TRANSVERSAL PRÓ-INFRA \# 01/2009) and Araucaria Foundation/PPSUS/SESA-PR/MS-Decit/CNPq (\# 04/2013). 
TITLE: Postural sway, balance confidence and fear of falling in women with knee osteoarthritis in comparison to matched controls.

\section{ABSTRACT}

Background: Osteoarthritis (OA) is a chronic degenerative disease that commonly affects the knee joints. Individuals over 65 years with knee OA have a greater risk of falls. However, there has be limited examination of the parameters of postural sway (increased time, speed and postural sway area (center of pressure area $(\mathrm{CoP}))$, and $\mathrm{OA}$ of the knee. Objectives: Primary: to determine whether the CoP variables discriminate between patients with knee OA and matched healthy volunteers, and to correlate the CoP variables with the Activities-Specific Balance Confidence Scale (ABC) and Falls Self-Efficacy Scale (FES); Secondary: to compare the $\mathrm{CoP}$ of the older women with OA with a control group in bipedal support condition with eyes opened and closed.

Design: Cross-sectional study.

Setting: University Biomechanics Laboratory.

Participants: Twenty-two participants were divided into two groups of 11: OA group $(\bar{x}=68$ years $(\mathrm{SD}=7.4)$ and a control group $(\bar{x}=66$ years $(\mathrm{SD}=4.4)$.

Methods: Static postural balance was measured by a portable force platform. Data were collected in both visual conditions (eyes open and closed), in a random order. Three attempts of 30 seconds were allowed for each participant on the force platform, with a one minute interval between attempts.

Main outcome measure: Variables the CoP: total displacement of sway (TDS, in $\mathrm{cm}$ ), anteroposterior amplitude displacement (APAD, in $\mathrm{cm}$ ), medial-lateral amplitude displacement (MLAD, in $\mathrm{cm}$ ), total mean velocity (TMV, in $\mathrm{cm} / \mathrm{s}$ ) and dispersion of the center of pressure (AREA, in $\mathrm{cm}^{2}$ ). 
50 Results: The postural sway analysis found statistically significant differences in the eyes open condition for the TDS ( $p=.020)$, APAD $(p=.042)$, TMV $(p=.010)$, and AREA $(p=.045)$ In the discriminant analysis none of $\mathrm{CoP}$ variables were able to classify the groups $(p=.15)$. The correlation analysis showed only the AREA with eyes closed was associated with the ABC Scale (rho=-0.42).

Conclusions: Women with knee OA had greater postural sway when compared to a control group for the eyes open condition. CoP variables could not discriminate between the groups. The AREA (dispersion of the center of pressure) was negatively correlated with the ABC Scale, when the eyes were closed.

Keywords: Osteoarthritis; Aged; Postural Balance; Knee.

\section{INTRODUCTION}

Osteoarthritis (OA) is a chronic degenerative joint disease commonly affecting the knee joint. OA leads to changes in the subchondral bone, cartilage loss, osteophyte development, inflammation of the synovium, meniscus injury, ligament laxity and muscle weakness [1]. For those affected, these joint changes often result in pain, functional limitation, decreased quality of life and work loss, which has a major economic impact [2]. Among the elderly, the prevalence of knee $\mathrm{OA}$ is approximately $12.2 \%$, with a higher prevalence in women $(14.9 \%)$ than in men $(8.7 \%)[3,4]$. Additionally it is reported that $11 \%$ of men and $17.9 \%$ of women may require knee arthroplasty due to changes caused by knee OA [3].

Postural or balance disturbance normally prompts an equilibrium reaction that may involve adjustments at the ankle, hip or stepping, depending on the muscle activation and 
the degree of postural disturbance. Postural sway can be assessed by questionnaires, physical/functional tests and computer software or directly from a force platform [5-8].

Although the relationship between knee OA and reduced balance is not fully understood, studies have shown that reduced quadriceps function and diminished proprioception are associated with a deterioration in balance (that is the ability to maintain the center of gravity within base of support with minimal sway or maximal steadiness) and can take the knee OA patient to an increased risk of falls [9-12].

It has also been reported that those with knee OA were more unstable, more disabled and had poorer functional performance than asymptomatic individuals $[6,13,14]$. Muscle performance, balance, and mobility impairments have been identified as factors that contribute to the risk of falls therefore, promoting regular physical activity may improve outcomes from treatment. A high prevalence of falls among those with knee OA is one factor that may contribute to the mobility limitations and difficulties with activities of daily living reported by Levinger et al. [15]. These authors showed that almost $50 \%$ of adults with severe knee OA had experienced a fall in the previous year, further Williams et al. [16], reported that in women, this number increased to two-thirds of those surveyed. Risk of falls is a major issue for those with knee OA $[15,16]$.

The relationship between balance and knee OA was explored by Khalaj et al. [6] who compared asymptomatic individuals with patients with knee OA. These authors found that there was a decrease in static and dynamic balance and greater impairment and higher risk of falls in individuals with moderate knee OA, when assessed by Overall Stability Index. This Index assesses subject's balance control using the Biodex Stability System on either static or unstable surface. Stability is determined from the center of mass excursion about the anterior- posterior and medial- lateral axes from the center point [17]. Hurley et al [13] also reported that people with OA $(n=103)$ had weaker quadriceps, poorer voluntary muscle 
activation and impaired acuity of knee joint position sense. These authors reported that of the 103 individuals with OA, only seventy six were able to complete the balance test, indicating poor stability and decreased balance control when compared to the control group, with a consequent increased risk of falls $[13,18]$. Wegener et al. [7] reported significant differences in postural sway between the OA and control group in the bipedal and unipodal conditions, with eyes closed. Similarly, Masui et al. [19] reported greater displacement in the center of pressure (CoP) in those with OA, with eyes closed and Hassan et al. [20] found that individuals with OA demonstrated increases in CoP displacement in the medial-lateral and anteroposterior direction.

In addition to the above mentioned changes, OA can lead to psychological changes due to the coping strategies adopted in the presence of chronic disease. The presence of chronic pain, can lead to an exacerbation of the sensation of pain and hypervigilance on bodily sensations which can contribute to fear avoidance beliefs and behaviours [21-23]. A study of 32 people with knee OA found that there was a moderate correlation between fear avoidance beliefs and pain, and a strong correlation between fear avoidance beliefs and functional limitation [24]. The psychological factors associated with chronic pain and OA reflect the individuals' perception and evaluation of their condition, directly influencing beliefs regarding ability to perform tasks (self-efficacy).

A number of authors have reported differences in CoP variables between those with OA and healthy controls, however, there are no studies to date that clearly demonstrate which $\mathrm{CoP}$ variables are able to discriminate between patients with knee OA and healthy individuals. Additionally further work is required to explore the relationship between direct measures of balance (force platform) and subjective measures of confidence in balance and risk of falls in those with knee OA. Thus, the primary aims of this study were: to determine whether the CoP variables discriminate between patients with knee OA and healthy 
125 individuals and to correlate the CoP variables with the Activities-Specific Balance

126 Confidence Scale (ABC) and Falls Self-Efficacy Scale (FES). The secondary aim of this

127 study was to compare the CoP of the older women with knee OA and a control group in

128 bipedal support condition with eyes opened and closed.

METHOD

131

Twenty-two participants in this cross-sectional study were equally divided into two groups: OA group $\left(\bar{x}=68\right.$ years $(\mathrm{SD}=7.4)$ and $\left.\bar{x}=30.2 \mathrm{~kg} / \mathrm{m}^{2}(\mathrm{SD}=6.3)\right)$ and a control group $\left(\bar{x}=66\right.$ years $(\mathrm{SD}=4.4)$ and $\left.\bar{x}=26.6 \mathrm{~kg} / \mathrm{m}^{2}(\mathrm{SD}=3.7)\right)$. The control group participants were recruited from the University Hospital and also from the local community. All participants were given information about the study and gave written informed consent, the study was approved by the Universidade Estadual de Londrina Ethics Committee (\#967/2014).The sample size was calculated through G*Power 3.1.9.2 [25] using a two-tailed Student $t$-test to find the mean difference between the two independent groups, an estimated effect size of $0.7, \alpha$ error prob. of 0.05 and $1-\beta$ error prob. of 0.85 . Twenty-one subjects were necessary for a power of $86 \%$.

The inclusion criteria for the OA group were: women, aged between 60 and 85 years a diagnosis of OA knee confirmed by the American College of Rheumatology (ACR) criteria and independently mobile. A rheumatologist confirmed the diagnostic of knee OA using the ACR - including the Kellgren-Lawrence radiographic criteria [26].

The exclusion criteria for both the OA and control groups were: surgical procedures

147 in the previous six months; chronic diseases such as coronary heart disease; rheumatic disease; cancer; chronic obstructive pulmonary diseases; uncontrolled hypertension; participating in physical activity programs in the previous two months (aerobic or resistance 
150

151

152

153

154

155

156

157

158

159

160

161

162

163

164

165

166

167

168

169

170

171

172

173

174

activity more than once a week for at least two months); arthroplasty and severe obesity (body mass index $\left.(\mathrm{BMI})>40 \mathrm{~kg} / \mathrm{m}^{2}\right)$.

The participants from the OA group were evaluated using The Western Ontario and

McMaster Universities Osteoarthritis Index (WOMAC) [27] for function; a 10cm pain

Visual Analog Scale (VAS) [28], marked in 1cm increments, used to record average pain (at rest); the Activities-Specific Balance Confidence Scale (ABC) [29], was used to measure balance in activities of daily living and the Falls Self-Efficacy Scale (FES) [30], was used to determine fear of falling.

Posturography was measured by kinetic data of the CoP, obtained through a portable force platform (Bertec Corporation ${ }^{\circledR}$, AM6500, USA), measuring 60x40x10 cm; and Fz = $5000 \mathrm{~N}, \mathrm{Fx}=\mathrm{Fy}=2500 \mathrm{~N}$, with a frequency of data acquisition of $1000 \mathrm{~Hz}$. Throughout data collection participants remained in the upright position on the force platform; the legs were positioned with the feet forming an angle of $30^{\circ}$ with a distance of approximately five $\mathrm{cm}$ between the heels and the arms at the sides of the body. Data were collected in both visual conditions (eyes open and closed), in a random order, and each participant was requested to maintain in an upright posture, as stable as possible, and keep their eyes fixed on a spot marked on a wall three meters away. Three attempts of 30 seconds were allowed for each participant on the force platform, with a one minute interval between attempts. The CoP signals were analyzed ten seconds after data acquisition began to avoid the possible effect of initial postural adjustments that could have altered the variables of CoP [8]. The variables analyzed were: total displacement of sway (TDS, length of the CoP on the support base, in $\mathrm{cm}$ ), anteroposterior amplitude displacement (APAD, distance between the maximum and minimum displacement of the $\mathrm{CoP}$ for anteroposterior direction, in $\mathrm{cm}$ ) and medial-lateral amplitude displacement (MLAD, distance between the maximum and minimum displacement of the $\mathrm{CoP}$ for medial-lateral direction, in $\mathrm{cm}$ ), total mean velocity 
175 (TMV, displacement of the total oscillation of the CoP in both directions divided by the total 176 time of the attempt, in $\mathrm{cm} / \mathrm{s}$ ) and dispersion of the center of pressure (AREA, estimates the 177 dispersion of the CoP data by calculating the stabilogram area, in $\mathrm{cm}^{2}$ ), as demonstrated in

Figure 1. For analysis, the data recorded from the force plate were amplified using a digital amplifier (Bertec ${ }^{\circledR}$ AM6800) and smoothed by a 4th order Butterworth filter and cutoff frequency stipulated by spectral analysis; then exported and processed in a specific routine developed in Matlab® software.

The Shapiro-Wilk test was used to verify normal distribution of the variables. When the assumption of normality was met, variables were presented as mean $(\bar{X})$ and standard deviation (SD), if not, in median (Md) and quartiles (25-75\%). For group comparison the Mann-Whitney test was used. The Spearman Correlation Coefficient (rho) was used to correlate the posturography variables and questionnaires (ABC and FES). Discriminant analysis was carried out using the Wilks' Lambda method to identify which of the variables related to the CoP would be able to significantly discriminate between the $\mathrm{OA}$ and control groups. The matrix of homogeneity was tested using the Box's M test of equality of covariance. Statistical significance was set at $5 \%$ and SPSS version 22.0 (IBM SPSS $^{\circledR}$, Armonk, NY, USA) was used in all analyses.

\section{RESULTS}

Twenty-two individuals participated in this study and data from the clinical examination (VAS, WOMAC, ABC and FES) of the OA group are shown in table 1. The Kellgren-Lawrence radiographic criteria indicated that most patients (58\%) had mild OA (grade 1 and 2); while the others (42\%) had severe stage of radiographic abnormalities (grade 3 and 4). Regarding the postural sway analysis, when the comparison between the 
groups was performed, statistically significant differences were found between all variables (TDS $(p=.020), \operatorname{APAD}(p=.042)$, TMV $(p=.010)$, and AREA $(p=.045))$ when evaluated in eyes open condition, except for MLAD ( $p=.061)$. The control group demonstrated better results (i.e. greater stability) when compared to patients with knee OA. However, when comparing the eyes closed condition, no statistically significant differences were found in any of the variables, as shown in table 2 .

The correlations between $\mathrm{CoP}$ variables and $\mathrm{ABC}$ questionnaire ranged from weak to strong. The strongest correlations were found in the eyes open condition, although this relationship was inversely proportional, that is, the better the $\mathrm{ABC}$ score, the worse was the performance in the CoP. Except for the TMV variable, where there was a better performance in the $\mathrm{CoP}$ for those patients with higher $\mathrm{ABC}$ scores $(r h o=.70)$. For the eyes closed condition, the performance was as expected, that is, the better $\mathrm{ABC}$ score, the better the performance in the CoP, but the correlations were weak. The FES questionnaire does not correlate with the CoP variables (table 3 ). When performing the multivariate analysis none of the variables were able to discriminate between groups (Wilks' Lambda $=.42 ; p=.15$ ).

\section{DISCUSSION}

The results of this study demonstrate that older women with knee OA presented greater postural sway with the eyes open when compared with healthy volunteers, in the closed eyes condition this difference was not observed. The results of the present study support previous work that reported increased postural sway in individuals with knee OA, with eyes open. Wegener et al. [7], Hinman et al. [5] and Masui et al. [19] found that participants with knee OA displayed higher postural sway than age matched controls under 
both the eyes open and closed conditions. In addition, Hurley et al. [13] reported increased postural sway only under the eyes open condition.

A possible explanation for these results may be that the tasks required different skills; with the eyes open the test evaluated the external-orientation perception, while with closed eyes there is greater reliance upon self-orientation perception. It has been shown that external-orientation perception is remarkably dependent on visual inputs associated with complete somatosensory input [31]. This may explain some of the differences between groups in the current study since both possessed intact visual inputs while the muscle and joint afferent input were changed. For self-orientation perception it could be expected that vestibular mechanisms compensate for the lack of visual input, however, vestibular disorders in patients were not controlled; this may account for the lack of observed differences between the groups in the eyes closed condition [32]. Another possibility is that patients with somatosensory disorders may increase "prior for upright" reference during self-orientation perception tasks [31]. On the other hand, no differences in posture variables in the eyes closed condition were observed although this has previously been reported. A possible explanation may be due to a lack of the standardization in CoP analysis methods such as differences in duration, number of repetitions and frequency acquisition.

The mean score of the questionnaires for this sample was 33 points for the FES (indicating risk of recurrent falls [30]) and 50\% for $\mathrm{ABC}$ (predictive of increased risk of falls [29]). Regarding the results of the correlations, there were no tenable relationships between questionnaires scores and CoP variables evaluated by force platform. An interesting inverse relationship between the $\mathrm{ABC}$ and $\mathrm{CoP} A \mathrm{AREA}$ was found: the better the $\mathrm{ABC}$ score, the worse was the performance in the CoP. This inverse correlation does not correspond to the clinical practice and this result does not have clinical relevance as an individual with high ABC scores should have better results in CoP variables. Many factors may have 
contributed to this finding, for example there may be a problem with the $\mathrm{ABC}$ questionnaire in terms of its validity (evaluation internal consistency and construct validity), or the presence of other conditions that may affect some components of the questionnaire such as self-efficacy, anxiety or depression, which were not controlled in this study. Both questionnaires assess self-efficacy, defined as a sense of confidence to perform a specific activity [33]. However, self-efficacy is highly modulated by self-regulation because the individual reacts not only to external stimuli, but also interprets and imposes self-direction, thereby modulating the behavior [34, 35].

Several studies have shown a relationship between self-efficacy and functionality, however, the CoP variables may not reflect function; it would be inappropriate therefore to relate the results of $\mathrm{CoP}$ variables to the confidence that the patient has to perform activities of daily living. Other factors have been demonstrated to correlate with knee OA and postural sway, pain, for example, was tested in previous studies with differing results. Hassan et al. [20] reported knee pain to be a significant predictor of increased postural sway in those with symptomatic OA compared to healthy individuals. However, Hinman et al. [5], Bennell [1] and Masui et al. [19] found no correlation between the degree of pain and balance deficit. Hassan et al. [20] showed that the presence of knee OA, obesity, and weak maximum voluntary contraction were the most significant independent predictors of increased postural sway - the model accounted for $47 \%$ of variation in lateral postural sway. Hinman et al. [5] tested correlations between the step test and postural sway and showed significant inverse relationships between the step test and seven of the twelve postural sway variables; however, the relationships were weak, indicating that the step test cannot accurately predict results obtained using the sway meter.

No CoP variable was able to discriminate between individuals with OA and healthy volunteers. Due to the sensitivity of the proportion of the sample in relation to the predictors 
variables presented in this study, type II error may have occurred even with the sample size calculation [36].

This study has some limitations that may compromise the results: vestibular and psychological disorders were not controlled in this sample and the $\mathrm{ABC}$ questionnaire was translated into Portuguese and tested only for reliability, not for its validity.

Further research that analyzes the relationship between functional tests in those with OA and questionnaires assessing self-efficacy should be conducted, however, with greater control of covariates that may influence the results. The findings of this study have some implications for clinical practice. The assessment of dynamic pain and the use of multidimensional, qualitative tools and health-related quality of life instruments are essential to better evaluate its impact on physical, emotional and social functions in those with OA. It is known that patients with somatosensory disorders show adaptations in motor control, therefore when treating patients with knee OA, tasks that require external-orientation perception are recommended, since afferent input from the muscles and joints take place under this condition and this reflects everyday life. Self-efficacy is influenced by: the results of previous performances, the experience of watching others, verbal feedback and the physiological state, however, this outcome does not reflect the performance of CoP variables. Postural control (evaluated by the force platform) does not seem to discriminate between individuals with knee $\mathrm{OA}$ and those without $\mathrm{OA}$, indicating that factors other than the $\mathrm{OA}$ are responsible for the balance disorders.

\section{CONCLUSION}

$$
\text { Patients with knee OA presented greater postural sway when compared to healthy }
$$
volunteers in the eyes open condition. No CoP variables were able to discriminate between 
patients with knee OA and those without OA. The correlations between the CoP variables and the $\mathrm{ABC} / \mathrm{FES}$ questionnaires ranged from weak to strong, however, these relationships are not meaningful.

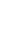

4

\section{REFERENCES}

[1]- Bennell KL, Hunter DJ, Hinman RS. Management of osteoarthritis of the knee. BMJ $2012 ; 345: \mathrm{e}-4934$.

[2]- Bennell KL, Hinman RS. A review of the clinical evidence for exercise in

osteoarthritis of the hip and knee. J Sci Med Sport 2011;14:1440-2440.

[3]- Quintana JM, Arostegui I, Escobar A, Azkarate J, Goenaga JI, Lafuente I. Prevalence of knee and hip osteoarthritis and the appropriateness of joint replacement in an older population. Arch Intern Med 2008;168:1576-84.

[4]- Felson DT, Zhang Y, Hannan MT, Naimark A, Weissman BN, Aliabaldi P, et al. The incidence and natural history of knee osteoarthritis in the elderly. Arthritis Rheum $1995 ; 38: 1500-5$.

[5]- Hinman RS, Bennell KL, Metcalf BR, Crossley KM. Balance impairments in individuals with symptomatic knee osteoarthritis: a comparison with matched controls using clinical tests. Rheumatology 2002;41:1388-94.

[6]- Khalaj N, Abu Osman NA, Mokhtar AH, Mehdikhani M, Wan Abas WA. Balance and risk of fall in individuals with bilateral mild and moderate knee osteoarthritis. PLoS One 2014;9:e92270. 
324 [7]- Wegener L, Kisner C, Nichols D. Static and dynamic balance response in persons with 325 bilateral knee osteoarthritis. J Orthop Sports Phys Ther 1997;25:13-8.

326 [8]- Rugelj D, Hrastnik A, Sevsek F, Vauhnik R. Reliability of modified sensory 327 interaction test as measured with force platform. Med Biol Eng Comput 2015;53:52534.

[9]- Walker CRC, Myles C, Nutton R, Rowe P. Movement of the knee in osteoarthritis. J Bone Joint Surg Br 2001;83:195-8.

[10]- Horak FB. Clinical measurement of postural control in adults. Phys Ther

[11]- Nashner L, Mccollum G. The organization of human postural movements: a formal basis and experimental synthesis. Behav Brain Sci 1985;8:135-72.

[12]- Turcot K, Sagawa Y Jr, Hoffmeyer P, Suva D, Armand S. Multi-joint postural behavior in patients with knee osteoarthritis. Knee 2015;22:517-21.

[13]- Hurley MV, Scott DL, Rees J, Newham DJ. Sensorimotor changes and functional performance in patients with knee osteoarthritis. Ann Rheum Dis 1997;56:641-8.

[14]- Pai YC, Rymer WZ, Chang RW, Sharma L. Effect of age and osteoarthritis on knee proprioception. Arthritis Rheum 1997;40:2260-5.

[15]- Levinger P, Menz HB, Wee E, Feller JA, Bartlertt JR, Bergaman NR. Physiological risk factors for falls in people with knee osteoarthritis before and early after knee replacement surgery. Knee Surg Sports Traumatol Arthrosc 2011;19:1082-9.

[16]- Williams SB, Brand CA, Hill KD, et al. Feasibility and outcomes of a home-based exercise program on improving balance and gait stability in women with lower limb osteoarthritis or rheumatoid arthritis: a pilot study. Arch Phys Med Rehabil. 2010; 91:106-114. 
[17]- Arnold BL, Schmitz RJ. Examination of balance measures produced by the Biodex Stability System. J Athl Train 1998;33:323-27.

[18]- Sharma L, Pai YC, Holtkamp K, Rymer WZ. Is knee joint proprioception worse in the arthritic knee versus the unaffected knee in unilateral knee osteoarthritis? Arthritis Rheum 1997;40:1518-25.

[19]- Masui T, Hasegawa Y, Yamaguchi J, Kanoh T, Ishiguro N, Suzuki S. Increasing postural sway in rural-community-dwelling elderly persons with knee osteoarthritis. J Orthop Sci 2006;11:353-8.

[20]- Hassan BS, Mockett S, Doherty M. Static postural sway, proprioception, and maximal voluntary quadriceps contraction in patients with knee osteoarthritis and normal control subjects. Ann Rheum Dis 2001;60:612-8.

[21]- Picavet HS, Vlaeyen JW, Schouten JS. Pain catastrophizing and kinesiophobia: Predictors of chronic low back pain. Am J Epidemiol 2002;156:1028-34.

[22]- Vlayen JW, Linton SJ. Fear-avoidance and its consequences in chronic musculoskeletal pain: a state of the art. Pain 2000;85:371-32.

[23]- Hatfield GL, Morrison A, Wenman M, Hammond CA, Hunt MA. Clinical tests of standing balance in the knee osteoarthritis population: systematic review and metaanalysis. Phys Ther 2016;96:324-37.

[24]- Bhatt NG, Shet MS, Vyas N. Correlation of fear avoidance beliefs with pain and physical function in subjects with osteoarthritis of knee. IJTRR 2015;4:117-21.

[25]- Faul F, Erdfelder E, Lang AG, Buchner A.G. G*Power 3: a flexible statistical power analysis program for the social, behavioral, and biomedical sciences. Behav Res Methods 2007;39:175-91.

[26]- Petersson IF, Boegård T, Saxne T, Silman AJ, Svensson B. Radiographic osteoarthritis of the knee classified by the Ahlbäck and Kellgren \& Lawrence systems for the 
tibiofemoral joint in people aged 35-54 years with chronic knee pain. Ann Rheum Dis 1997;56: 493-6.

[27]- Bellamy N, Buchanan WW, Goldsmith CH, Campbell J, Stitt LW. Validation study of WOMAC: A health status instrument for measuring clinically important patient relevant outcomes to antirheumatic drug therapy in patients with osteoarthritis of the hip or knee. J Rheumatol 1988;15:1833-40.

[28]- Boonstra A, Schiphorst PHR, Reneman MF, Posthumus JB, Stewart RE. Reliability and validity of the visual analogue scale for disability in patients with chronic musculoskeletal pain. Int J Rehabil Res 2008;31:165-9.

[29]- Marques AP, Mendes YC, Taddei U, Pereira CAB, Assumpção A. BrazilianPortuguese translation and cross cultural adaptation of the activities-specific balance confidence (ABC) scale. Braz J Phys Ther 2013;17:170-8.

[30]- Camargos FFO, Dias RC, Dias JMD, Freire MTF. Cross-cultural adaptation and evaluation of the psychometric properties of the Falls Efficacy Scale - International Among Elderly Brazilians (FES-I-BRAZIL). Rev Bras Fisioter 2010;14:237-43.

[31]- Bringoux L, Di Cesare CS, Borel L, Macaluso T, Sarlegna FR. Do visual and vestibular inputs compensate for somatosensory loss in the perception of spatial orientation? Insights from a deafferented patient. Front Hum Neurosci 2016;10:181.

[32]- Auvray M and Harris LR. The state of the art of sensory substitution. Multisens Res 2014;27:265-9.

[33]- Bandura A. Health promotion by social cognitive means. Health Educ Behav 2004;31:143-64.

[34]- Bandura A, Adams N. Analysis of self-efficacy theory of behavioral change. Cognitive Ther Res 1977;1:287-310. 
397 [35]- Bandura A, Adams N, Beyer J. Cognitive processes mediating behavioral change. J $398 \quad$ Pers Soc Psychol 1977;35:125-39.

399 [36]- Pua YH, Cowan SM, Wrigley TV, Bennell KL. Discriminant validity of the Western 400 Ontario and McMaster Universities Osteoarthritis index physical functioning subscale 401 in community samples with hip osteoarthritis. Arch Phys Med Rehabil 2009;90:1772402 7.

403

404 
405

406

407

408

409

410

411

412

413

414

415

416

417

418

419

420

421

422

423

424

425

\begin{tabular}{lc}
\hline & OAG $(\mathrm{n}=11)$ \\
& $\bar{x}(\mathrm{SD})$ \\
\hline VAS $(\mathrm{cm})$ & $5(2)$ \\
WOMAC & $32(18.75)$ \\
ABC $(\%)$ & $50(24.56)$ \\
FES & $33(11.01)$
\end{tabular}

Table 1. Baseline scores in pain, function, balance and self-efficacy in participants with

Osteoarthritis group (OAG); Visual analog scale (VAS); Western Ontario and McMaster Universities Osteoarthritis Index (WOMAC); Activities-Specific Balance Confidence Scale (ABC) and Falls SelfEfficacy Scale (FES). knee osteoarthritis 
427 Table 2. Comparison of CoP variables between the knee osteoarthritis group and the control group.

\begin{tabular}{|c|c|c|c|c|c|c|}
\hline & \multicolumn{3}{|c|}{$\mathbf{E O}(n=11)$} & \multicolumn{3}{|c|}{$\mathbf{E C}(\mathrm{n}=11)$} \\
\hline & $\begin{array}{c}\text { OAG } \\
\text { Md }(25-75 \%)\end{array}$ & $\begin{array}{c}\text { CONTROL } \\
\text { Md }(25-75 \%)\end{array}$ & $p$ & $\begin{array}{c}\text { OAG } \\
\text { Md }(25-75 \%)\end{array}$ & $\begin{array}{c}\text { CONTROL } \\
\text { Md }(25-75 \%)\end{array}$ & $p$ \\
\hline TDS (cm) & $36.70(30.27-56.43)$ & $26.93(18.03-33.36)$ & .020 & $46.62(35.23-63.93)$ & $44.80(24.92-56.32)$ & .62 \\
\hline APAD $(\mathrm{cm})$ & $1.98(1.79-4.22)$ & $1.77(1.27-2.63)$ & .042 & $3.15(2.55-4.60)$ & $2.68(1.86-3.37)$ & .08 \\
\hline MLAD (cm) & $1.98(1.62-3.26)$ & $1.42(1.22-1.99)$ & .061 & $2.63(1.74-3.91)$ & $1.91(1.30-2.41)$ & .12 \\
\hline $\mathrm{TMV}(\mathrm{cm} / \mathrm{s})$ & $1.73(0.70-2.07)$ & $0.89(0.60-1.11)$ & .010 & $1.55(1.17-2.13)$ & $1.49(0.83-1.87)$ & .62 \\
\hline $\operatorname{AREA}\left(\mathrm{cm}^{2}\right)$ & $4.22(2.39-12.65)$ & $1.83(1.22-3.70)$ & .045 & $5.27(3.07-6.89)$ & $3.44(1.68-6.06)$ & .17 \\
\hline
\end{tabular}



429 displacement (APAD); Medial-lateral amplitude displacement (MLAD), Total mean velocity (TMV) and Dispersion of the center of pressure (AREA). 
431 Table 3. Correlations between $\mathrm{CoP}$ variables and $\mathrm{ABC}$ and FES questionnaires.

\begin{tabular}{|c|c|c|}
\hline CoP Variables & ABC & FES \\
\hline \multicolumn{3}{|l|}{ EO } \\
\hline TDS (cm) & $.56(.31 ; .80)$ & $.09(-.15 ; .33)$ \\
\hline $\operatorname{APAD}(\mathrm{cm})$ & $.29(.04 ; .53)$ & $.17(-.07 ; .41)$ \\
\hline $\operatorname{MLAD}(\mathrm{cm})$ & $.55(.30 ; .79)$ & $.04(-.20 ; .28)$ \\
\hline $\mathrm{TMV}(\mathrm{cm} / \mathrm{s})$ & $.70(.45 ; .94)$ & $.08(-.16 ; .32)$ \\
\hline $\operatorname{AREA}\left(\mathrm{cm}^{2}\right)$ & $.40(.15 ; .64)$ & $.18(-.06 ; .42)$ \\
\hline \multicolumn{3}{|l|}{ EC } \\
\hline TDS $(\mathrm{cm})$ & $-.24(-.48 ; .005)$ & $-.06(-.30 ; .18)$ \\
\hline $\operatorname{APAD}(\mathrm{cm})$ & $-.07(-.31 ; .17)$ & $-.33(-.57 ;-.08)$ \\
\hline $\operatorname{MLAD}(\mathrm{cm})$ & $-.28(-.52 ;-.03)$ & $-.11(-.35 ; .13)$ \\
\hline $\mathrm{TMV}(\mathrm{cm} / \mathrm{s})$ & $-.26(-.50 ;-.01)$ & $-.10(-.34 ; .14)$ \\
\hline $\operatorname{AREA}\left(\mathrm{cm}^{2}\right)$ & $-.41(-.63 ;-.16)$ & $-.07(-.31 ; .17)$ \\
\hline
\end{tabular}

432 Center of pressure (CoP); Activities-specific balance confidence scale (ABC); Falls self-efficacy scale (FES); 433 Confidence interval of 95\% (95\% CI); Eyes opened (EO); Eyes closed (EC); Total displacement of sway (TDS); 434 Antero-posterior amplitude displacement (APAD); Medial-lateral amplitude displacement (MLAD) and Total 435 mean velocity (TMV). 


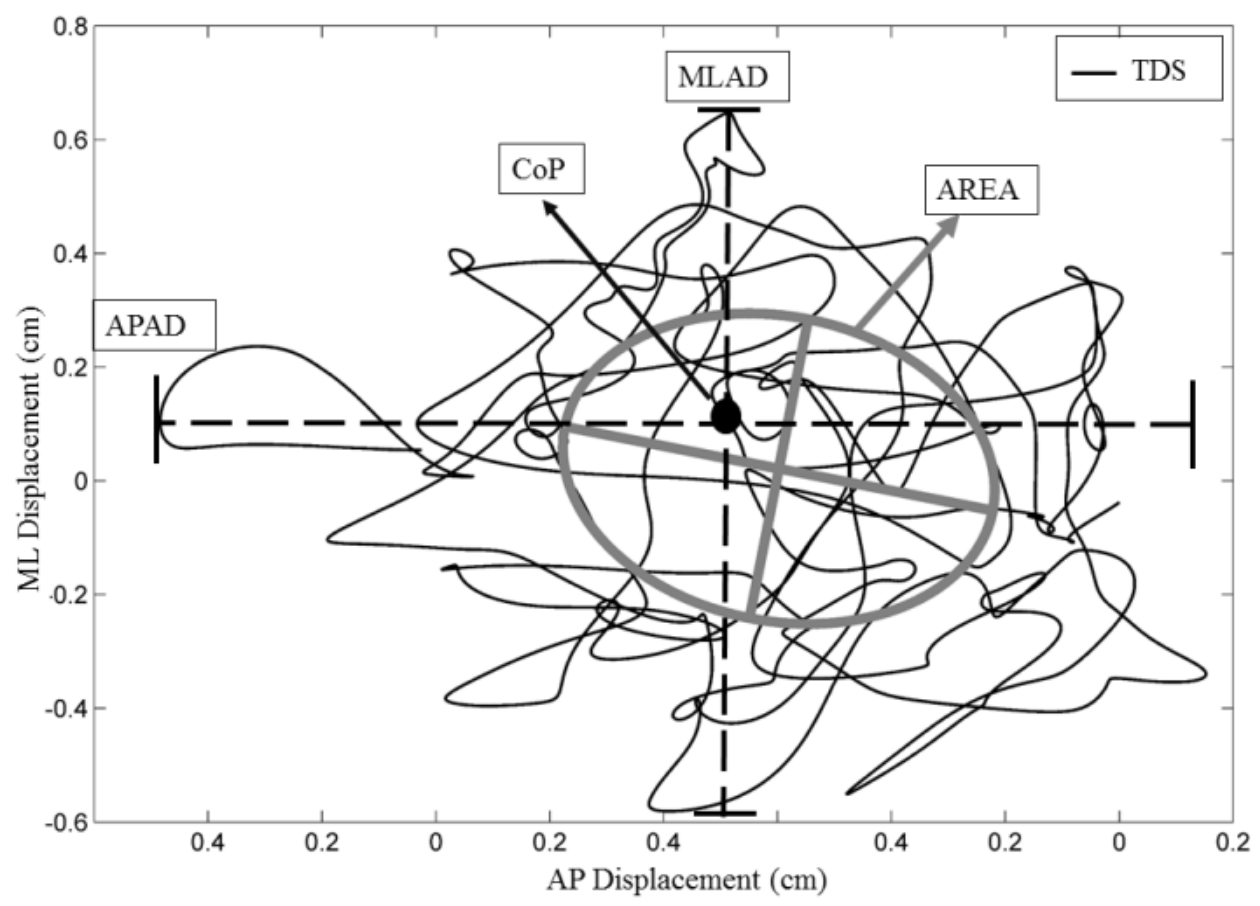

438

440 Figure 1. Posturography data of the different variables included in the analyses. AP:

441 anteroposterior; ML: medial-lateral; TDS: total displacement of sway; APAD:

442 anteroposterior amplitude displacement; MLAD: medial-lateral amplitude displacement;

443 CoP: center of pressure and AREA: dispersion of the center of pressure. 